\title{
Development, Physicochemical Characterization and Sensory Evaluation of a Red Wine Using Roselle (Hibiscus Sabdariffa) and Peppermint (Mentha Piperita L.) Extract
}

\author{
Tirna Purkait ${ }^{1}$, Sangeeta Pandey ${ }^{2}$ \\ ${ }^{l}$ M.Sc. Food Science \& Nutrition, Department of Nutrition and Dietetics, Mount Carmel College Autonomous, \\ Bangalore-560052, India, ${ }^{2}$ Head of the Department, PG Food Science \& Nutrition, Department of Nutrition and \\ Dietetics, Mount Carmel College Autonomous, Bangalore-560052, India
}

\begin{abstract}
Wine is called as a functional fermented food as it shows several health benefits. This fermented undistilled alcoholic beverage is produced by anaerobic fermentation of grape sugars to ethanol by the wine yeast. In this study, roselle (Hibiscus sabdariffa) and peppermint (Mentha piperita L.) extract were used for making the wine along with main ingredients to obtain nine variations of wine. All the ingredients are best known for their medicinal and nutritional benefits. Baker's yeast (Saccharomyces cerevisiae) was used for the fermentation process. Each variation along with the standard red wine (control) was fermented for 28 days. Characterization properties like $\mathrm{pH}$ and Total Soluble Solids were measured and observed weekly. After 28 days, sensory evaluation was conducted for the developed variations. The results showed that the variations with $10 \%$ of roselle were found to be the most accepted and amongst them, red wine with $10 \%$ roselle and $6 \%$ of peppermint extract (V2T3) was the best selected one by sensory panelists. The final products for all the variations and control were tested to measure their $\mathrm{pH}$, specific gravity, alcohol content and vitamin $\mathrm{C}$. The $\mathrm{pH}$, specific gravity and alcohol by volume (\%) of the most accepted variation (V2T3) were 2.96, 1.006 and $10.73 \%$ respectively. The results indicate developed red wine was accepted by the panelists.
\end{abstract}

Keywords: Fermentation; Sensory; Roselle; Peppermint; Wine.

\section{Introduction}

Grapes have been widely used as a prime raw ingredient for production of making wines over a long period of time. Traditionally, red wine is produced from grape varieties that have black or red color and the fermentation is carried out on the skin using standard wine yeast. Despite that, studies have investigated the suitability of other fruits, vegetables, edible flowers or combination of two or more substrates can be used to produce wine for example mango wine, roselle wine,banana wine etc. Edible flowers have traditionally been used in different cultures, such as European and Asian, to improve the appearance (colour, odor and flavour) and nutritional value of food. Flowers are served as a salad, as a snack and as a side dish. For example, roselle, otherwise called Indian sorrel belongs to the Malvaceceae family and develops in the tropic and subtropical locales of the world. It is an erect, extended sub-woody yearly bush that bears alternate leaves and blooms that are borne with leafy large calyces. It is popularly recognized as 'mesta' or 'chukur' in Indian subcontinent including Bangladesh. Roselle calyces are palatable and the traditional use of roselle calyces (fresh or dried) extends from its use in remedies for various diseases to food uses such as sauce or filling for tarts or pies; and also to jam, jelly, syrup, wine, ice cream and flavours. The nutritional composition of fresh calyces varies from study to study, probably due to various varieties, genetic, environmental, and ecological and plant harvesting. In early studies, protein $(1.9 \mathrm{~g} / 100 \mathrm{~g})$, fat $(0.1 \mathrm{~g} / 100 \mathrm{~g})$, carbohydrate $(12.3 \mathrm{~g} / 100 \mathrm{~g})$ and fiber $(2.3 \mathrm{~g} / 100 \mathrm{~g})$ were reported. They are rich in vitamin $\mathrm{C}$ $(14 \mathrm{mg} / 100 \mathrm{~g})$, calcium $(1.72 \mathrm{mg} / 100 \mathrm{~g})$, beta carotene $(300 \mu \mathrm{g} / 100 \mathrm{~g})$ and iron $(57 \mathrm{mg} / 100 \mathrm{~g})^{[1]}$. Peppermint or mint (Mentha piperita L.), a perennial aromatic herb belonging to the Lamiaceae (Labiatae) family, is 
a natural hybrid between spearmint (Mentha spicata L.) and water mint (Mentha aquatic L.). Fortification of wines is common but doing the same to improve its beneficial health properties is still less explored. A study has been done where orange wines were fortified with herbal extracts like holybasil, lemon-grass, peppermint and ginger were chosen which are known for therapeutic and medicinal applications. These herbal extracts impart theirbenificial properties to the fortified wines and hence, consumption of such fortified wines would give tremendous health benefits than regular wines ${ }^{[2]}$.

\section{Materials and Method}

Sample collection and preparation: Fresh grapes were purchased, destemmed, soaked in warm water and salt $(\mathrm{NaCl})$ for 10 minutes, washed with clean water, dried in a clean muslin cloth and sorted. Grapes were weighed accurately and crushed and mashed by a clean wooden muddler in a clean and dry vessel. Dried Roselle petals were purchased from market and weighed accurately according to the calculated concentration of the respected variation and it is crushed and mashed along with the grapes nicely with the help of the muddler. Sugar $(75 \mathrm{~g})$ and sterilized warm water $(500 \mathrm{ml})$ were added to the mixtures after this. Thus the total soluble solids (TSS) of the mashes were adjusted.

Table 1. Composition of variations

\begin{tabular}{|l|c|c|c|}
\hline $\begin{array}{l}\text { Product } \\
\text { Code }\end{array}$ & Grapes (kg) & Roselle (\%) & $\begin{array}{l}\text { Peppermint } \\
\text { extract (\%) }\end{array}$ \\
\hline T0 (Standard) & 1 & - & - \\
\hline V1T1 & 1 & 5 & 2 \\
\hline V1T2 & 1 & 5 & 4 \\
\hline V1T3 & 1 & 5 & 6 \\
\hline V2T1 & 1 & 10 & 2 \\
\hline V2T2 & 1 & 10 & 4 \\
\hline V2T3 & 1 & 10 & 6 \\
\hline V3T1 & 1 & 15 & 2 \\
\hline V3T2 & 1 & 15 & 4 \\
\hline V3T3 & 1 & 15 & 6 \\
\hline
\end{tabular}

Before inoculation, Potassium metabisulfite was added in the mashes to reduce the bacterial contamination. Commercially available baker's yeast (Saccharomyces cerevisiae) suspension (1g/l) is added to it and mixed well. The wine must was filled into sterilized fermentation jars and sealed airtight and left to incubate for 28 days at room temperature. After 28 days the filtration was done of each variation and the amount of extract obtained from each variation was measured by measuring cylinder. Peppermint extract was made from fresh peppermint leaves which were purchased from the market and destemmed, soaked in warm water and salt for 5 minutes, washed with clean water, dried in a clean muslin cloth and sorted. For each variation apart from control, around 10 gm leaves were measured and taken for crushing. The leaves were crushed uniformly by adding water. Afterward, it was added to $200 \mathrm{ml}$ distilled water and boiled. It was separated with the assistance of filter paper. The extract was thus prepared and could now be included. The extract was made just before adding to wine to guarantee it was included when fresh.

Pasteurization and bottling: The clear wine was transferred into covered steel potsand pasteurized by heating to $70^{\circ} \mathrm{C}$ for 15 minutes and cooled to room temperature $\left(25^{\circ} \mathrm{C}\right)$. No chemical was added for the clarification of wines. Cold wines were filled into presterilized bottles and kept in room until needed for further analysis.

Determination of the physiochemical properties: Determination of $\mathrm{pH}$ and total soluble solids (TSS), specific gravity $(S G)$ and alcohol by volume \% (ABV\%): The $\mathrm{pH}$ and TSS were measured according to the AOAC method $^{[3]}$. Specific gravity (SG) of different wine versions was determined according to the procedure of Balogu and Towobola, 2017 ${ }^{[4]}$ and ABV\% was then calculated based on specific gravity chart given by American Society for Brewing Chemists ${ }^{[5]}$.

Sensory evaluation: Each panelist received the wine sample in a random presentation order, a glass of water for rinsing consumption between samples. Coded samples were assessed organoleptically using a 9-point hedonic scale.

\section{Results and Discussions}

Physicochemical Properties: $p H$ : The $\mathrm{pH}$ of wine is important to know as it plays a critical role in many aspects of wine making, in particular wine stability. $\mathrm{pH}$ influences microbiological stability, influences the solubility of proteins and affects red wine colour and oxidative and browning reactions. Table 2 shows the weekly data of the $\mathrm{pH}$ for developed wines and it was observed that the wines are on acidic side (below 7) and in the variations the $\mathrm{pH}$ ranges from $2.8-3$. The significant trend which was observes here was the $\mathrm{pH}$ was decreasing gradually throughout the fermentation 
period. Due to the low $\mathrm{pH}$ values, the wines gave a crisp tart taste to the product and it also enhances the microbial resistance of the product. The values are comparable with the $\mathrm{pH}$ values on the final day were 3.0 and 3.07 at $20^{\circ} \mathrm{C}$ and $30^{\circ} \mathrm{C}$ respectively in roselle wine ${ }^{[6]}$. The $\mathrm{pH}$ of 3 varieties of Zobo drink ranges from 2.5-2.67 [7].

Table 2. Weekly pH

\begin{tabular}{|l|c|c|c|c|c|}
\hline Product Code & Week 1 & Week 2 & Week 3 & Week 4 & Final pH \\
\hline T0 & $3.53 \pm 0.057$ & $3.46 \pm 0.057$ & $3.36 \pm 0.057$ & $3.13 \pm 0.057$ & $3.2 \pm 0.1$ \\
\hline V1T1 & $3.16 \pm 0.057$ & $3.13 \pm 0.057$ & $3.09 \pm 0.01$ & $3.04 \pm 0$ & $3.01 \pm 0.1$ \\
\hline V1T2 & $3.26 \pm 0.057$ & $3.16 \pm 0.057$ & $3.086 \pm 0.01$ & $3.07 \pm 0.057$ & $3.05 \pm 0.005$ \\
\hline V1T3 & $3.23 \pm 0.057$ & $3.13 \pm 0.057$ & $3.03 \pm 0.057$ & $3.09 \pm 0$ & $3.06 \pm 0.005$ \\
\hline V2T1 & $3.09 \pm 0.005$ & $3.08 \pm 0.057$ & $3.04 \pm 0$ & $3 \pm 0.1$ & $2.93 \pm 0.005$ \\
\hline V2T2 & $3.08 \pm 0.015$ & $3.06 \pm 0.057$ & $3.05 \pm 0.01$ & $2.99 \pm 0.1$ & $2.93 \pm 0.057$ \\
\hline V2T3 & $3.13 \pm 0.06$ & $3.08 \pm 0.057$ & $3.06 \pm 0.011$ & $2.99 \pm 0.015$ & $2.96 \pm 0.057$ \\
\hline V3T1 & $3.04 \pm 0.017$ & $3.01 \pm 0.057$ & $2.9 \pm 0.011$ & $2.89 \pm 0.015$ & $2.8 \pm 0.1$ \\
\hline V3T2 & $3.05 \pm 0.01$ & $3.003 \pm 0.057$ & $2.94 \pm 0.011$ & $2.85 \pm 0.057$ & $2.82 \pm 0.1$ \\
\hline V3T3 & $3.04 \pm 0.011$ & $3.01 \pm 0.057$ & $2.96 \pm 0.02$ & $2.87 \pm 0.057$ & $2.84 \pm 0.005$ \\
\hline
\end{tabular}

Total soluble solids ( ${ }^{\circ}$ Brix): TSS measures the sugar content of present in the wine. This is measured using a refractometer, and is referred to as the degrees Brix $\left({ }^{\circ}\right)$. This influences the conversion of sugar to alcohol by yeast strain during fermentation period.

Table 3. Initial and final TSS

\begin{tabular}{|l|c|c|}
\hline Product Code & Initial TSS (Brix $^{\mathbf{0}}$ ) & Final TSS Brix $^{\mathbf{}}$ ) \\
\hline T0 & 21.54 & 2.2 \\
\hline V1T1 & 19.31 & 2.01 \\
\hline V1T2 & 19.31 & 2.04 \\
\hline V1T3 & 19.31 & 2.03 \\
\hline V2T1 & 20.43 & 2.19 \\
\hline V2T2 & 20.43 & 2.02 \\
\hline V2T3 & 20.43 & 2.01 \\
\hline V3T1 & 20.88 & 2.18 \\
\hline V3T2 & 20.88 & 2.05 \\
\hline V3T3 & 20.88 & 2.03 \\
\hline
\end{tabular}

Table 3 shows the initial and final total soluble solids (TSS) of the developed wines. The initial brix $\left({ }^{\circ}\right)$ of the wines were to check the total soluble solids present in the wine musts before fermentation. The standard (T0) showed the highest initial brix of 21.54 followed by variation 3, variation 2 and variation 1 . The final TSS of the wines has come down drastically in the final wines. The addition of sugar at the beginning of fermentation is necessary to provide suitable conditions for the growth of yeast and fermenting the sugar into ethanol ${ }^{[8]}$.

Specific gravity and Alcohol by Volume \% (ABV\%): Table 4 shows the data for specific gravity (SG) of the developed wines. Final specific gravity is observed to be on a lower side than the initial specific gravity which is taken from the initial wine must. There is no significant trend observed in the specific gravity of wine. The standard wine had the highest initial SG of 1.09 amongst all the developed products, followed by variation 3 (1.087), variation 2 (1.085) and variation 1 (1.08). Thetable also depicts alcohol by volume \% (ABV $\%$ ) of the developed wines. The standard (T0) has showed to obtain the highest $\%$ of alcohol by volume $\%$ (ABV $\%$ ) having an $\mathrm{ABV}$ of $11.27 \%$ which is almost near to the variations V3T2 (11.005\%) and V3T3 (11.14\%). This value is comparable with the wine produced from a blend of pawpaw and roselle extracts with a value of $10.5 \%(\mathrm{w} / \mathrm{v})$ alcohol ${ }^{[9]}$. 
Table 4. Specific gravity and Alcohol by Volume \% (ABV \%)

\begin{tabular}{|l|c|c|c|}
\hline Product Code & Initial Specific Gravity & Final Specific Gravity & ABV\% \\
\hline T0 & 1.09 & 1.007 & 11.27717 \\
\hline V1T1 & 1.08 & 1.006 & 10.05435 \\
\hline V1T2 & 1.08 & 1.006 & 10.05435 \\
\hline V1T3 & 1.08 & 1.005 & 10.19022 \\
\hline V2T1 & 1.085 & 1.007 & 10.59783 \\
\hline V2T2 & 1.085 & 1.006 & 10.7337 \\
\hline V2T3 & 1.085 & 1.006 & 10.7337 \\
\hline V3T1 & 1.087 & 1.007 & 10.86957 \\
\hline V3T2 & 1.087 & 1.006 & 11.00543 \\
\hline V3T3 & 1.087 & 1.005 & 11.1413 \\
\hline
\end{tabular}

Sensory score analysis: Table 5 depicts the product wise mean sensory scores. While considering the mean sensory score with respect to taste, the highest score $(8.04 \pm 0.94)$ was obtained by V2T3, followed by standard (T0) which obtains a mean score of $7.48 \pm$ 1.64. V3T2 got the minimum mean score with respect to aroma $(4.60 \pm 1.26)$. The statistical $\mathrm{f}$-test indicates that the mean sensory scores with respect to aroma were found to be statistically significant at $5 \%$ level $(\mathrm{p}<0.05$, $\left.20.64^{*}\right)$. While considering the mean sensory score with respect to mouthfeel, the highest score $(8.12 \pm$ 0.83 ) was obtained by V2T3, followed by standard (T0) which obtains a mean score of $7.44 \pm 1.53$. V1T1 got the minimum mean score with respect to mouthfeel (4.041 $\pm 1.48)$.

Table 5. Product wise mean sensory score

\begin{tabular}{|l|c|c|c|c|}
\hline \multirow{2}{*}{ Product Code } & \multicolumn{4}{|c|}{ Sensory Scores } \\
\cline { 2 - 5 } & Aroma & Taste & Mouth feel & Colour \& Appearance \\
\hline T0 & $7.20 \pm 1.58$ & $7.48 \pm 1.64$ & $7.44 \pm 1.53$ & $7.84 \pm 1.18$ \\
\hline V1T1 & $6.32 \pm 1.15$ & $5.48 \pm 1.50$ & $4.041 \pm 1.48$ & $7.08 \pm 1.22$ \\
\hline V1T2 & $6.24 \pm 1.09$ & $5.96 \pm 1.51$ & $5.88 \pm 1.04$ & $7.12 \pm 0.93$ \\
\hline V1T3 & $6.12 \pm 1.05$ & $5.84 \pm 1.11$ & $5.68 \pm 1.31$ & $6.84 \pm 1.28$ \\
\hline V2T1 & $6.76 \pm 1.30$ & $6.96 \pm 1.27$ & $6.84 \pm 1.03$ & $7.60 \pm 0.76$ \\
\hline V2T2 & $7.04 \pm 1.10$ & $7.08 \pm 1.19$ & $7.00 \pm 1.08$ & $7.68 \pm 0.69$ \\
\hline V2T3 & $7.88 \pm 1.01$ & $8.04 \pm 0.94$ & $8.12 \pm 0.83$ & $8.24 \pm 0.93$ \\
\hline V3T1 & $5.60 \pm 1.63$ & $4.68 \pm 1.35$ & $4.72 \pm 1.49$ & $6.88 \pm 1.59$ \\
\hline V3T2 & $5.68 \pm 1.41$ & $4.60 \pm 1.26$ & $4.56 \pm 1.45$ & $6.84 \pm 1.21$ \\
\hline V3T3 & $5.68 \pm 1.41$ & $5.00 \pm 1.47$ & $4.88 \pm 1.51$ & $6.88 \pm 1.13$ \\
\hline F-Test & $8.56^{*}$ & $20.64 *$ & $22.35^{*}$ & $5.01^{*}$ \\
\hline SEm \pm & 0.2585 & 0.2676 & 0.2592 & 0.2245 \\
\hline CD at 5\% & 0.7166 & 0.7418 & 0.7185 & 0.6223 \\
\hline
\end{tabular}

*Significant at $5 \%$ Level, SEm: Standard Errors of mean, CD: Critical Difference 
The statistical f-test indicates that the mean sensory scores with respect to aroma were found to be statistically significant at $5 \%$ level $\left(\mathrm{p}<0.05,22.35^{*}\right)$. While considering the mean sensory score with respect to colour and appearance, the highest score $(8.24 \pm 0.93)$ was obtained by V2T3, followed by standard (T0) which obtains a mean score of $7.84 \pm 1.18$. V1T3 and V3T2 got the minimum mean score with respect to colour and appearance $(6.84 \pm 1.28$ and $6.84 \pm 1.21)$. The statistical f-test indicates that the mean sensory scores with respect to aroma were found to be statistically significant at $5 \%$ level $\left(\mathrm{p}<0.05,5.01^{*}\right)$.

Appearance, colour, aroma, taste and subtle taste factors like flavour of wine constitute the quality. Aroma and taste of wines are very complex and depend on number of factors such as cultivar, vinification practices, fermentation and maturation ${ }^{[10]}$.

Table 6. Sensory score of overall acceptance

\begin{tabular}{|l|c|c|}
\hline \multirow{2}{*}{ Products } & \multicolumn{2}{|c|}{ Overall Acceptability Scores } \\
\cline { 2 - 3 } & Mean & SD \\
\hline T0 & 7.512 & 1.38 \\
\hline V1T1 & 6.124 & 1.09 \\
\hline V1T2 & 6.260 & 1.01 \\
\hline V1T3 & 6.140 & 0.93 \\
\hline V2T1 & 7.064 & 0.90 \\
\hline V2T2 & 7.220 & 0.87 \\
\hline V2T3 & 8.092 & 0.84 \\
\hline V3T1 & 5.492 & 1.19 \\
\hline V3T2 & 5.444 & 0.90 \\
\hline V3T3 & 5.628 & 0.98 \\
\hline F-Test & \multicolumn{2}{|c|}{0.2040} \\
\hline SEm \pm & \multicolumn{2}{|l}{0.5655} \\
\hline CD at 5\% & \\
\hline
\end{tabular}

*Significant at $5 \%$ Level, SEm: Standard Errors of mean, CD: Critical Difference

The table 6 depicts the overall mean acceptability scores with respect to the products. The findings show that the highest overall mean acceptability score was found to be higher in V2T3 (8.092 \pm 0.84$)$, followed by T0 (7.512 \pm 1.38$)$. However, the least accepted product with minimum mean sensory score was found to be V3T2 (5.444 \pm 0.90$)$. The data subjected for statistical tests reveals the difference in overall acceptability. The scores between products were found to be statistically significant at $5 \%$ level $\left(\mathrm{p}<0.05,20.30^{*}\right)$.
From the sensory scores it can be concluded that V2T3 was the best acceptable variation in all the attributes and panelists liked the product more than the standard (T0). The bitterness imparted by the $10 \%$ roselle in the product was well balanced by the addition of $6 \%$ peppermint extract with its cooling effect. In variation 1 the proportion of 5\% roselle, grapes and peppermint extract was not well balanced which made the product less acceptable to the panelists and in variation 3 use of $15 \%$ roselle in the product showed reduced acceptance by the panelists as it imparted bitterness which made the variation unacceptable.

\section{Conclusion}

There are plenty of fruits, vegetables and edible flowers which are still underutilized though they can show positive health effects when consumed as it contains plenty of vitamins, minerals and also shows antioxidative properties. This study proves that acceptable wines can be prepared by addition of roselle and peppermint extract in the normal red wines if added in specific amount. The high acidity of the wines indicated that microbial spoilage resistance and storability can be improved when roselle is added to wine. Further studies are needed to check the proximate analysis and mineral compositions of wine and also to check the parameters of the wine when aged for a longer time.

Ethical Clearance: Passed through internal research committee

\section{Source of Funding: Self \\ Conflict of Interest: Nil}

\section{Reference}

1. Ismail A, Ikram E, Nazri H. Roselle (Hibiscus sabdariffa L.) seeds nutritional composition protein quality and health benefits. Food. 2008;2(1):1-16.

2. Shiradhonkar R, Dukare A, Jawalekar K, Magar P, Jadhav H. Fortification of Wine with Herbal Extracts: Production, Evaluation and Therapeutic applications of such Fortified Wines. IOSR Journal of Environmental Science, Toxicology and Food Technology. 2014;8(3):09-14.

3. Horowitz W., editor. AOAC official method of analysis. 17th ed. Gaithersburg, MD: Association of Official Analytical Chemists International; 2000.

4. Balogu TV, Towobola O. Production and quality analysis of wine from honey and coconut milk blend 
using Saccharomyces cerevisiae. Fermentation. 2017 Jun;3(2): 16.

5. American Society for Brewing Chemists (ASBC). Method of Analysis of ABSC.14th ed.Saint Paul, MN, USA: ASBC;2011.

6. Ifie I, Marshall LJ, Ho P, Williamson G. Hibiscus sabdariffa (Roselle) extract and wine: phytochemical profile, physicochemical properties and carbohydrase inhibition. Journal of Agricultural and Food Chemistry. 2016;64(24):4921-31.

7. Foline O, Rachael A, Muhummad R, Eunice B. The nutritional quiality of three varieties of zobo (Hibiscus sabdariffa L.) subjected to the same preparation condition. American Journal of food technology. 2011;6(8):705-8.

8. Tatdao P, Norraset S, Tiwawan S. Physico-chemical and sensory properties of musts and wines from Melodorum fruticosum Lour. International Food Research Journal. 2014 Jan 1;21(1).

9. Okoro CE. Production of red wine from roselle (Hibiscus sabdariffa) and pawpaw (Carica papaya) using palm-wine yeast (Saccharomyces cerevisiae). Nig. Food J.2007; 25(2):158-164.

10. Jackson, R. S. Wine tasting: a professional handbook. Academic Press; 2016. 